\title{
Socio-demographic, behavioral, and mental health and wellbeing correlates of university student binge drinking: does frequency matter?
}

\author{
Jason D. Edgerton* and Lance W. Roberts \\ Department of Sociology, University of Manitoba, Winnipeg, Manitoba, Canada
}

\begin{abstract}
Objectives: To assess whether the relationships between binge drinking and various socio-demographic, behavioral, attitudinal, mental health and wellbeing correlates differ according to frequency of binge drinking.

Methods: This study $(n=507)$ used survey data collected from a convenience sample of undergraduate students at a mid-western urban Canadian university. Ordinal logistic regression was conducted with frequency of binge drinking as the outcome variable.

Results: Binge drinking frequency was positively associated with impulsivity, negative alcohol-related consequences, and life satisfaction and negatively associated with religiosity. "Frequent" binge drinkers (14.8\%) were 2.7 times more likely to have smoked cigarettes, 1.5 times more likely to have used other drugs, 1.8 times more likely to have engaged in "risky" sex, and to have had a negative gambling-related experience than "occasional" binge drinkers (57.8\%), who were, in turn, proportionally more likely to have reported these behaviors and/or experiences than non-binge drinkers (28\%).

Conclusion: Although there were a number of correlates that were related to frequency of binge drinking as predicted, the expected relationships between mental health and wellbeing and binge drinking frequency were not evident. Future research should seek to assess to what extent this is due to methodological issues and to what extent it is due the particularities of university drinking culture that promotes binge drinking as normative and adaptive, engendering higher tolerance for what constitutes problematic alcohol use, and the implications of this for alcohol education and treatment on campus.
\end{abstract}

\section{Introduction}

A number of studies examine the prevalence of binge drinking and its correlates among American university students; however, there is a dearth of Canadian studies. Most Canadian research uses the 1998 and 2004 Canadian Campus Survey, or older, datasets [1-3]. Moreover, existing Canadian studies focus on establishing the prevalence of alcohol use among Canadian university students [4], rather than exploring bivariate or multivariate levels of analysis of binge drinking.

The present study builds on our recent work [5] which used logistic regression analysis to compare binge drinking to non-binge drinking university students on a number of socio-demographic, behavioral, mental health and wellbeing correlates. Against expectations, we did not find any significant differences between binge and non-binge drinkers in terms of mental health (e.g. depression, anxiety, positive mental health) socio-demographic (e.g. gender, living with parents, being Canadian born) or behavioral (e.g. smoking cigarettes, using other drugs, or having "risky" sex) variables. However, we did find significant differences in terms of religiosity, impulsivity, life satisfaction, and alcohol-related problems; binge drinkers were less religious, more impulsive, reported more negative alcohol-related consequences, and higher life satisfaction. We posited that one reason for the apparent lack of significant differences between binge drinkers and non-binge drinkers, particularly regarding mental health and wellbeing, might be due to the dichotomous nature of the binge drinking outcome variable. We suggested that use of a more graduated measure of binge drinking, one that captures differences in frequency of binge drinking, might better enable detection of such differences, if they exist. Building on this recommendation the present study conducts an ordinal logistic regression analysis to assess whether the relationship between alcohol consumption and various socio-demographic, behavioral, mental health and wellbeing correlates, differs according to frequency of binge drinking.

Previous research suggests the following hypotheses regarding correlates of university student binge drinking:

\section{Socio-demographics:}

1. Being male, born in Canada, not living with one's parents, and having a family member with alcohol problems will each be associated with increased probability of frequent binge drinking $[1,2,6]$.

\section{Mental health and wellbeing:}

2. Positive affect, positive mental health, life satisfaction, and self esteem will be negatively associated with frequency of binge drinking;

Correspondence to: Jason Edgerton, Ph.D., Associate Professor, Department of Sociology, University of Manitoba, Winnipeg, Manitoba, Canada; E-mail: J.Edgerton@umanitoba.ca

Key words: binge drinking frequency, mental health and wellbeing, alcohol-related consequences, Canadian university students, ordinal logistic regression

Received: December 12, 2016; Accepted: December 27, 2016; Published: December 30, 2016 
that is, higher scores on measures of each will be associated with decreased probability of frequent binge drinking $[7,8]$.

3. Negative affect, anxiety, depression, impulsivity, and social alienation will be positively associated with frequency of binge drinking; that is, higher scores on measures of each will be associated with increased probability of frequent binge drinking [7,9-11].

\section{Behaviors and attitudes}

4. Religiosity will be negatively associated with frequency of binge drinking, with higher religious faith scores being negatively associated with probability of frequent binge drinking [12].

5. Engaging in risky sex, consuming cigarettes and other drugs, and having reported at least one gambling-related negative consequence in the previous year will each be associated with increased probability of more frequent binge drinking $[13,14]$.

6. Age of first alcohol consumption/intoxication will be negatively associated with probability of frequent binge drinking; that is, the older the reported age of first consumption the lower the probability of frequent binge drinking [14].

7. GPA will be negatively associated with probability of frequent binge drinking [2].

8. The number of reported alcohol-related negative consequences will be positively associated with probability of frequent binge drinking [15].

\section{Method}

\section{Data}

The current study $(\mathrm{n}=507)$ uses data from the Student Leisure and Well-Being Survey (SLWBS) administered to undergraduate students at a mid-western urban Canadian university. Comparison of the SLWBS sample to available institutional demographics (Table 1) suggests the data are reasonably representative of the general university population.

\section{Analytical procedures}

All statistical analyses were conducted with SPSS 24. An insignificant Little's MCAR test indicated that missing data were missing completely at random, but to preserve sample size and power, multiple imputation was used to generate 20 datasets from which final model estimates were pooled. The analysis aimed to assess which correlates differentiate non-binge drinkers, occasional binge drinkers, and frequent binge drinkers in the sample of Canadian university students. Accordingly, multivariate analysis was conducted using ordinal logistic regression.

Ordinal logistic regression is an extension of the basic logistic regression model, allowing for analysis of a categorical outcome that has 3 or more ordered categories. The ordered outcome categories in the present study are: non-binge drinker, occasional binge drinker, and frequent binge drinker. The present analysis employs a cumulative logit

Table 1. Comparison of SLWBS Sample with University Population on key Demographic Characteristics.

\begin{tabular}{|l|c|c|}
\hline & SLWBS sample & University* \\
\hline Female & $65 \%$ & $54 \%$ \\
\hline Full- vs. part-time & $82.6 \%$ vs. $17.4 \%$ & $88.4 \%$ vs. $11.6 \%$ \\
\hline $\begin{array}{l}\text { International vs. Canadian } \\
\text { Students }\end{array}$ & 15.4 vs. $84.6 \%$ & $15.1 \%$ vs. $84.9 \%$ \\
\hline Ages $18-24$ & $88.7 \%$ & $77.3 \%$ \\
\hline
\end{tabular}

* provided by the Office of Institutional Analysis at the sampled university (or proportional odds) model. The cumulative logit model assumes that slope coefficients for independent variables (and thus the odds ratios) are equal across categories of the dependent variable; that is, the odds of being in one category as opposed to the next (higher) category are the same irrespective of which two categories are being compared [16]. A test of proportional odds indicated that this assumption was satisfied (the null hypothesis of parallel lines was retained in all 20 imputed datasets) and that ordinal logistic regression was appropriate for this data.

\section{Measures}

\section{Binge drinking}

Based on previous research, an incident of binge drinking was defined for males as having consumed 5 or more alcohol drinks in one session, and for females as having consumed 4 or more drinks in one session or sitting [5,17]. Respondents were asked how often they had consumed this amount over the past 30 days: "0 times," " 1 time," "2-3 times," "1-2 times per week," "3-4 times per week," " $5+$ times per week." Responses were coded into 3 categories as 'non-binge-drinker' $=0$ ( 0 times), 'occasional binge drinker' $=1$ ( 1 to 3 times $)$, or 'frequent binge drinker' $=2$ (1-2 times per week or more).

\section{Socio-demographics}

The socio-demographic variables included in the analysis were gender, immigrant status, family history of alcohol problems, living arrangements, and GPA. With the exception of GPA, sociodemographics were coded into dichotomous variables with female, Canadian-born, indicating a member of one's family has an alcohol problem, and living with parents coded to one, respectively.

\section{Mental health and wellbeing}

Two measures of mental health disorders were included in the analysis, depression and anxiety. Anxiety was measured using the GAD-7 anxiety scale $(\alpha=.90)$ a seven-item index [18]. Depression was measured using the Center for Epidemiologic Studies Depression Scale (CES-D scale), a 20-item index $(\alpha=.91)$ [19]. For both indices, high scores indicate high levels of disorder.

Four measures of mental wellbeing were included in the analysis. Positive and negative affect ( $\alpha=.87, .82$, respectively) were measured using the Positive and Negative Affect Schedule short-form (PANAS short-form) [20]; life satisfaction was measured using the Diener's Satisfaction with Life Scale (SWLS) $(\alpha=.87)$ [21]; positive mental health was measure using the Mental Health Continuum Short Form (MHCSF) $(\alpha=.92)$ [22]. In addition, social alienation was measured using the Social Alienation Scale ( $\alpha=.83$ ) [23], and self-esteem was measured using the Rosenberg Self-Esteem Scale (RSE) $(\alpha=.89)$ [24].

Finally, impulsivity was measured using the Barratt Impulsiveness Scale (BIS-11), a 26 -item index $(\alpha=.82)$ with higher summative scores indicating greater levels of impulsivity [25].

\section{Behaviors and attitudes}

Religiosity was measured using the Santa Clara Strength of Religious Faith (SCOSORF) questionnaire [26], a 10-item index measuring the level of religious faith among respondents $(\alpha=.98)$. The measure ranged from 0 to 30, with 30 indicating the strongest level of religiosity.

"Risky" sexual behavior was computed by combining two variables-measures of unprotected and unplanned sexual relations $(\alpha=.71)$. Respondents were ask whether, in the past 12 months, they 
had, while under the influence of alcohol, engaged in (a) unplanned sex or (b) unprotected sex with a person they did not know before. The risky sexual behavior variable was coded into a dichotomous variable, with those answering 'yes' to one or both of the risky sexual behavior items receiving a score of 1 and those answering 'no' to both measures receiving a score of 0 .

Drug and Alcohol Use. A number of variables were used to measure experiences with drugs and alcohol. The validated shorter 18-item version of Rutgers Alcohol Problem Index (RAPI) was used to measure the number of alcohol-related consequences $(\alpha=.88)$ [27]. Early experiences with alcohol were measured using one variable: the age at which one first became intoxicated from alcohol. Drug use was measured by two dichotomous variables: tobacco cigarette use ("yes" = 1) and use of other drugs including marijuana, heroin, and cocaine (use of one or more $=1$ ).

Gambling Problems. Measured by the Problem Gambling Severity Index (PGSI), a 9-item subscale contained within the Canadian Problem Gambling Index (CPGI) [28]. Possible scores on the PGSI range from 0 to 27 , with higher scores indicating greater severity of risk for problem gambling ( $\alpha=.91$ ). The score is derived from Likert scale items where the respondent is presented with a number of negative consequences of gambling and asked to indicate whether they have experienced any in the past 12 months, response options are 'never', 'sometimes', 'most of the time', or 'almost always'. In the present analysis PGSI scores were dichotomized, so that anyone who answered 'sometimes' to at least one negative consequence (i.e. a raw PGSI score of at least 1) received a code of 1 , while those who answered 'never' to all questions were coded 0 .

Grade Point Average was coded using the high school average for participants that were only in their first year of university, and using university GPA for participants that indicated they were in their second year or beyond. The categories ranged from 4.0 to 4.5 (or A/A+), 3.5 to 3.9 (or B+), 3.0 to 3.4 (or B), 2.5 to 2.9 (or C+), 2.0 to 2.4 (or C), and 1.0 to 1.9 (or D or lower).

\section{Results}

In our sample $83.1 \%$ of respondents reported consuming alcohol in the previous 12 months, and $69.7 \%$ of these students reported engaging in binge drinking at least once in the previous 30 days. There were no significant gender differences among the $28 \%$ of respondents categorized as non-binge-drinkers, the $57.2 \%$ of respondents categorized as occasional binge drinkers (reported binge drinking 1 to 3 times in the previous month), nor the $14.8 \%$ categorized as frequent binge drinkers (reported binge drinking 1-2 times a week or more in the previous month) (Table 2).

Means, proportions, and standard errors for modeled predictor variables-overall and broken down by binge drinking category-are reported in Table 2. Correlations are reported in Figure 1. As expected, impulsiveness and number of negative alcohol related consequences were positively associated with frequency of binge drinking, while religiosity and age of first alcohol consumption were negatively associated with frequency of binge drinking. Also as expected, having reported at least one gambling-related problem, consumption of cigarettes and other drugs, and having engaged in risky sex were all associated with higher frequency of binge drinking. Contrary to expectations, neither satisfaction with life, nor any of the mental health and well-being variables were significantly correlated with frequency of binge drinking, as was also true of all the demographic variables.

Ordinal logistic regression results are reported in Table 3. Consistent
Table 2. Means and Proportions of Correlates by Drinking Category.

\begin{tabular}{|c|c|c|c|c|}
\hline & $\begin{array}{c}\text { Non-Binge } \\
\mathrm{n}=142\end{array}$ & $\begin{array}{c}\text { Occasional } \\
\mathrm{n}=290\end{array}$ & $\begin{array}{c}\text { Frequent } \\
\mathrm{n}=75\end{array}$ & $\begin{array}{c}\text { Overall } \\
\mathrm{N}=507\end{array}$ \\
\hline $\begin{array}{l}\text { Continuous } \\
\text { Correlates }\end{array}$ & Mean (SD) & Mean (SD) & Mean (SD) & Mean (SD) \\
\hline Positive Affect & $12.343(3.499)$ & $12.684(3.447)$ & $12.667(3.434)$ & $12.581(3.453)$ \\
\hline Negative Affect & $6.562(3.572)$ & $6.674(3.241)$ & $6.827(3.426)$ & $6.707(3.359)$ \\
\hline $\begin{array}{l}\text { Positive Mental } \\
\text { Health }\end{array}$ & $46.828(13.071)$ & $47.347(11.832)$ & $45.384(11.906)$ & $46.759(12.175)$ \\
\hline Anxiety & $8.907(5.400)$ & $9.025(5.690)$ & $9.865(5.508)$ & $9.087(5.563)$ \\
\hline Depression & $17.814(11.201)$ & $17.521(10.494)$ & $18.797(9.903)$ & $18.043(10.495)$ \\
\hline Religious Faith & $14.181(10.504)$ & 8.837 (9.104) & $7.747(8.091)$ & $10.226(9.692)$ \\
\hline Impulsivity & $29.087(10.576)$ & $32.483(9.374)$ & $38.423(9.318)$ & $32.536(10.181)$ \\
\hline Life Satisfaction & $11.619(1.903)$ & $12.324(3.980)$ & $12.437(4.077)$ & $12.065(4.111)$ \\
\hline Social Alienation & $25.600(8.958)$ & $24.634(8.873)$ & $25.732(7.762)$ & $25.090(8.727)$ \\
\hline Self Esteem & $19.295(5.651)$ & $19.645(5.301)$ & $18.933(5.381)$ & $19.420(5.422)$ \\
\hline RAPI & $1.725(3.757)$ & $3.389(4.784)$ & $9.155(7.777)$ & $3.845(5.712)$ \\
\hline Age 1st Consumption & $16.683(1.903)$ & $16.123(2.231)$ & $14.787(2.196)$ & $16.105(2.218)$ \\
\hline GPA & $3.500(1.344)$ & $3.649(1.234)$ & $3.176(1.465)$ & $3.518(1.307)$ \\
\hline $\begin{array}{l}\text { Dichotomous } \\
\text { Correlates }\end{array}$ & $\begin{array}{l}\text { Proportion } \\
\text { (SE) }\end{array}$ & $\begin{array}{l}\text { Proportion } \\
\text { (SE) }\end{array}$ & $\begin{array}{l}\text { Proportion } \\
\text { (SE) }\end{array}$ & $\begin{array}{l}\text { Proportion } \\
\text { (SE) }\end{array}$ \\
\hline PGSI & $.070(.258)$ & $.130(.340)$ & $.360(.483)$ & $.150(.355)$ \\
\hline Risky Sex & $.037(.189)$ & $.110(.314)$ & $.324(.471)$ & $.122(.328)$ \\
\hline Drugs & $.246(.432)$ & $.448(.498)$ & $.747(.438)$ & $.438(.497)$ \\
\hline Cigarettes & $.079(.271)$ & $.224(.418)$ & $.587(.496)$ & $.239(.427)$ \\
\hline Born in Canada & $.230(.421)$ & $.200(.813)$ & $.009(.293)$ & $.190(.662)$ \\
\hline Gender (Female) & $.670(.471)$ & $.650(.478)$ & $6009.493)$ & $.650(.479)$ \\
\hline $\begin{array}{l}\text { Live with parents/ } \\
\text { guardians }\end{array}$ & $.700(.460)$ & $.770(.422)$ & $.680(.470)$ & $.740(.439)$ \\
\hline $\begin{array}{l}\text { Family Alcohol } \\
\text { Problems }\end{array}$ & $.402(.492)$ & $.434(.497)$ & $.527(.503)$ & $.442(.498)$ \\
\hline \multicolumn{5}{|l|}{ Note: pooled estimates } \\
\hline
\end{tabular}

Table 3. Logistic Coefficients for Correlates (pooled estimates).

\begin{tabular}{|l|l|c|c|c|}
\hline Correlate & $\begin{array}{l}\text { Logistic } \\
\text { Coefficients }\end{array}$ & $\begin{array}{c}\text { Standard } \\
\text { Error }\end{array}$ & $\begin{array}{c}\text { Odds } \\
\text { Ratio }\end{array}$ & 95\% CI \\
\hline PGSI & $.596^{*}$ & .290 & 1.815 & $1.027-3.203$ \\
\hline Positive Affect & -.002 & .046 & .998 & $.912-1.092$ \\
\hline Negative Affect & -.004 & .043 & .996 & $.916-1.084$ \\
\hline Positive Mental Health & -.009 & .014 & .991 & $.964-1.020$ \\
\hline Anxiety & -.007 & .025 & .993 & $.945-1.044$ \\
\hline Depression & -.010 & .019 & .990 & $.955-1.027$ \\
\hline Religious Faith & $-.038^{* * *}$ & .011 & .963 & $.943-.983$ \\
\hline Impulsivity & $.045^{* * *}$ & .011 & 1.046 & $1.023-1.069$ \\
\hline Social Alienation & -.009 & .017 & .991 & $.960-1.024$ \\
\hline Self Esteem & .008 & .031 & 1.008 & $.948-1.071$ \\
\hline Risky Sex & $.588^{*}$ & .326 & 1.800 & $.950-3.411$ \\
\hline Drugs & $.393^{*}$ & .233 & 1.481 & $.940-2.34$ \\
\hline Cigarettes & $1.020^{* * *}$ & .273 & 2.773 & $1.626-4.730$ \\
\hline Life Satisfaction & $.065^{*}$ & .034 & 1.067 & $.999-1.140$ \\
\hline RAPI & $.102^{* * *}$ & .022 & 1.107 & $1.061-1.156$ \\
\hline Born in Canada & -.317 & .281 & .728 & $.420-1.264$ \\
\hline Age 1st Consumption & -.045 & .051 & .956 & $.865-1.058$ \\
\hline Gender (Female) & .106 & .214 & 1.111 & $.731-1.692$ \\
\hline Live with parents/guardians & .166 & .220 & 1.181 & $.767-1.817$ \\
\hline GPA & -.035 & .078 & .966 & $.829-1.126$ \\
\hline Family Alcohol Problems & -.191 & .204 & .826 & $.554-1.232$ \\
\hline Pseud R Cox and Snel & $312 ;$ & & \\
\hline
\end{tabular}

Pseudo $\mathrm{R}^{2}:$ Cox and Snell $=.312 ;$ Nagelkerke $=.366$

${ }^{a}$ Odds ratios were calculated for 1 unit increase in predictors

$* \mathrm{p} \leq .05, * * \mathrm{p} \leq .01, * * * \mathrm{p} \leq .001$ (one-tailed)

with our hypotheses, religious faith was negatively associated with frequency of binge drinking; that is, each 1 unit increase in religious faith score was associated with a significant decrease $(4 \%)$ in the 
Figure 1. Correlation Matrix.

\begin{tabular}{|c|c|c|c|c|c|c|c|c|c|c|c|c|c|c|c|c|c|c|c|c|c|c|}
\hline Variable & 1 & 2 & 3 & 4 & 5 & 6 & 7 & 8 & 9 & 10 & 11 & 12 & 13 & 14 & 15 & 16 & 17 & 18 & 19 & 20 & 21 & 22 \\
\hline 1. Binge Frequency & - & & & & & & & & & & & & & & & & & & & & & \\
\hline 2. PGSI & $.231^{* *}$ & - & & & & & & & & & & & & & & & & & & & & \\
\hline 3. Positive Affect & .035 & .022 & - & & & & & & & & & & & & & & & & & & & \\
\hline 4. Negative Affect & .019 & .017 & $-.457 * *$ & - & & & & & & & & & & & & & & & & & & \\
\hline 5. Pos Mental Health & -.028 & -.034 & $.770^{* *}$ & $-.512^{* *}$ & - & & & & & & & & & & & & & & & & & \\
\hline 6. Anxiety & .046 & .067 & $-.352^{* *}$ & $.595 * *$ & $-.384^{* *}$ & - & & & & & & & & & & & & & & & & \\
\hline 7. Depression & .031 & .040 & $-.581^{* *}$ & $.709 * *$ & $-.626^{* *}$ & $.695^{* *}$ & - & & & & & & & & & & & & & & & \\
\hline 8. Religions Faith & $-237 * *$ & -.046 & .022 & -.008 & .039 & -.025 & -.033 & - & & & & & & & & & & & & & & \\
\hline 9. Impulsivity & $.292^{* *}$ & $.177^{* * *}$ & $-158^{* *}$ & $.273^{* *}$ & $-290^{*+*}$ & $.209^{* *}$ & $.310^{* *}$ & -.067 & - & & & & & & & & & & & & & \\
\hline 10. Social Alienation & -.008 & .045 & $-.508^{* *}$ & $.454^{* *}$ & $-.592^{* *}$ & $.449^{* *}$ & $.629 * *$ & -.021 & $.330^{* *}$ & - & & & & & & & & & & & & \\
\hline 11. Self Esteem & -.011 & .010 & $.582^{* *}$ & $-.591 * *$ & $.658^{* *}$ & $-.553^{* *}$ & $-.724^{* *}$ & .065 & $-.332 * *$ & $-.676^{* *}$ & - & & & & & & & & & & & \\
\hline 12. Risky Sex & $.254^{* *}$ & $.184^{* *}$ & .028 & .016 & .031 & .022 & .040 & $-.118^{* *}$ & $.172^{* *}$ & .030 & .007 & - & & & & & & & & & & \\
\hline 13. Drugs & $.314^{* *}$ & $.123^{* *}$ & -.032 & $.113^{*}$ & -.082 & $.123^{* *}$ & $.159 * *$ & $-255 * *$ & $200^{* *}$ & $.093^{*}$ & $-146 * *$ & $.216^{* *}$ & - & & & & & & & & & \\
\hline 14. Cigarettes & $.355 * *$ & $.182^{* *}$ & .002 & .073 & $-.089 *$ & $.141^{* *}$ & $.120^{*}$ & $-147 *$ & $.189 * *$ & .042 & $-.103^{*}$ & $.157 *$ & $.431^{* *}$ & - & & & & & & & & \\
\hline 15. Life Satisfaction & .056 & -.030 & $.575^{* *}$ & $-.462^{* *}$ & $.601 * *$ & $-347^{* *}$ & $-.540 * *$ & .060 & $-212^{* *}$ & $-.522^{* *}$ & $.617 * *$ & .011 & $-131^{* *}$ & -.072 & - & & & & & & & \\
\hline 16. RAPI & $.383 * *$ & $266^{* *}$ & -.084 & $.180^{* *}$ & $-140^{* * x}$ & $.193^{* *}$ & $.210^{* *}$ & -.076 & $.277 * *$ & .075 & $-144^{* *}$ & $.301^{* *}$ & $.318^{* *}$ & $.359 * *$ & -.077 & - & & & & & & \\
\hline 17. Born in Canada & -.061 & -.018 & .065 & .005 & .055 & -.037 & -.045 & $.185 * *$ & .007 & .048 & -.081 & -.060 & $-107 *$ & -.012 & -.036 & -.074 & - & & & & & \\
\hline 18.Age 1st Consum & $-268 * *$ & $-.178^{* *}$ & -.034 & $.101^{*}$ & -.007 & -.020 & .002 & $.211^{* *}$ & $-184^{* *}$ & .007 & -.026 & $-200 *$ & $-316^{* *}$ & $-293 *$ & $-.096^{*}$ & $-.189 * *$ & $-.099 *$ & - & & & & \\
\hline 19. Gender & -.047 & $-.179 * *$ & -.059 & $.189 * *$ & $-.091 *$ & $.217^{* *}$ & $.193^{* *}$ & .081 & -.005 & $.107 *$ & $-206 *$ & $-.143 * *$ & .019 & -.027 & -.062 & -.025 & -.026 & -.051 & - & & & \\
\hline 20. Live w/ parents & .007 & .045 & .023 & .020 & .023 & .086 & .030 & .031 & .002 & .046 & -.027 & -.002 & -.017 & -.004 & .016 & -.047 & -.014 & -.030 & -.008 & - & & \\
\hline 21. GPA & -.056 & -.073 & .085 & $-.103 *$ & $.168^{* *}$ & -.040 & $-.111^{*}$ & -.031 & $-184^{* *}$ & $-.135 *$ & $.147^{* *}$ & -.014 & $-169 * *$ & -.082 & $.193^{*}$ & -.042 & -.012 & .026 & .044 & $.142^{* *}$ & - & \\
\hline 22. Family Alc Probs & .074 & .057 & $-106^{* *}$ & $.115^{*}$ & $-175 * z$ & $.100^{*}$ & $.115^{*}$ & $.127 * *$ & $.101^{*}$ & $.150^{* *}$ & $-123^{* *}$ & .021 & $.119^{* *}$ & $.163^{* *}$ & $-157 * *$ & $.215^{* *}$ & -.073 & $-.094^{*}$ & .075 & $-110^{*}$ & -.043 & \\
\hline
\end{tabular}

probability of being in the frequent (vs. occasional) or occasional (vs. non-binge drinker) category. Likewise, impulsivity was, as predicted, positively associated with frequency of binge drinking, with each 1 unit increase in BIS-11 scores associated with a significant increase (5\%) in the probability of being in the next higher binge drinking frequency category. Finally, the number of alcohol-related negative consequences was positively associated with increased frequency of binge drinking, with each 1 unit increase in RAPI scores associated with an increased probability (11\%) of being in a higher binge drinking category.

Also as hypothesized, engaging in risky sex, smoking cigarettes, and having experienced gambling-related negative consequences were associated with more frequent binge drinking. That is, frequent binge drinkers were 2.7 times more likely to have smoked cigarettes, 1.5 times more likely to have used other drugs, 1.8 times more likely to have engaged in risky sex, and 1.8 times more likely to have had a negative gambling-related experience in the previous 12 months than occasional binge drinkers, who were, in turn, proportionally more likely to have reported these behaviors and/or experiences than nonbinge drinkers. None of the hypothesized relationships between the mental health and wellbeing variables and binge drinking frequency were supported by the data. Interestingly, life satisfaction, which was not significantly related to binge drinking frequency at the bivariate level, was significantly associated with binge drinking frequency at the multivariate level, but not in the expected negative directionlife satisfaction was actually positively related to frequency of binge drinking, with a 1 unit increase in life satisfaction score associated with a significant increase in the probability (7\%) of membership in a higher binge drinking category. None of the demographic variables (gender, Canadian born, living with parent, GPA, age of first consumption, family alcohol problems) were significantly related to frequency of binge drinking, nor was having reported consuming drugs.

\section{Discussion}

Although older research reported greater rates of binge drinking among males, the increasing use of gender weighted measures of binge drinking and recent trends in university student drinking patterns suggest-consistent with present findings-that this gap is closing $[17,29]$. None of the other socio-demographic variables-living with parents, being born in Canada, history of family alcohol problems-are associated with differences in frequency of binge drinking.
Surprisingly, only one hypothesis regarding the relationships between the mental health/wellbeing variables and frequency of binge drinking is supported by the data. Impulsivity is positively related to binge drinking, with higher impulsivity being associated with increased probability of binge drinking and/or more frequent drinking. This finding is in line with previous Canadian results [30]. Interestingly, the relationship between life satisfaction and frequency of binge drinking is insignificant at the bivariate level, but significant at the multivariate level, although not in the expected negative directionwith life satisfaction increasing slightly with binge frequency. While this contradicts some previous findings [9], it fits with other evidence suggesting that university students may attribute positive social consequences to alcohol consumption $[31,32]$ and that some amount of binge drinking is accepted as a normal aspect of college culture and social integration into the collegiate community $[7,33]$.

Several other proposed research hypotheses are supported by the data. Consistent with previous Canadian studies [12], the present findings indicate a negative relationship between religious faith and binge drinking, with the probability of binge drinking (vs. non-binge drinking) and/or more frequent binge drinking (vs. occasional binge drinking) decreasing as strength of religious faith increases. Also as hypothesized, and in keeping with previous Canadian findings [15], binge drinking and/or more frequent binge drinking is associated with higher frequency of alcohol-related negative consequences-such as not being able to complete homework or study for a test, getting into a fight, causing shame or embarrassment to someone, neglecting responsibilities, and missing a day of school or work. Additionally, smoking cigarettes, using other drugs, engaging in risky sex and negative gambling-related consequences are all positively associated with binge drinking: frequent binge drinkers are 2.7 times more likely to have smoked cigarettes, 1.5 times more likely to have used other drugs, and 1.8 times more likely to have engaged in risky sex and to have experienced at least one negative gambling-related consequence (e.g. chasing loses, health and/or financial problem) than occasional binge drinkers, who, in turn, are proportionally more likely to have reported these behaviors and/or experiences than non-binge drinkers. The link between cigarettes, drug use and binge drinking echoes previous findings $[14,34]$, and the association between problematic gambling behavior and alcohol use is well-documented [13] but evidence of a connection between binge drinking and risky sex-more 
frequent binge drinking is associated with greater probability of having engaged in risky sex-is a novel finding in a Canadian university sample-although in line with previous non-Canadian findings [14].

The findings of this study are subject to the limitations of crosssectional self-report surveys, and due caution should be exercised in generalizing from a single university sample to all Canadian university students. Also, while the absence of negative associations between mental health/wellbeing and frequency of binge drinking was unexpected, it may be due to the insensitivity of self-report measures used. Students who engage in excessive alcohol consumption often do not see themselves as having an alcohol problem [35], tend to overestimate the average amount alcohol that a typical university student consumes [36,37], and often have higher thresholds for what they consider heavy drinking to be [38]. It could be that the attenuation of social benefits and the mounting negative effects on health and wellbeing manifest more palpably (and perhaps undeniably) at more intense levels of binge drinking and so went undetected in the present study due to the small number of very frequent binge drinkers in the sample. A larger sample, with a proportionally larger subsample of very frequent binge drinkers (comprising an additional "very frequent" ordinal category) might provide the statistical power necessary to detect problematic associations, if they exist. It may also be that the relationships between mental health and wellbeing and heavy alcohol consumption are affected by motivations and normative perceptions about alcohol consumption [37,39,40], and future research should include such measures. Additionally, data could be collected from both university students and university-aged non-students to help distinguish developmental effects of emerging adulthood [41] from the contextual effects of the university environment $[42,43]$. Finally, our understanding of possible causal linkages would benefit greatly from longitudinal data that would enable consideration of the temporal ordering of relationships and tracking changes over time, such as how drinking behavior, and its correlates, fluctuate over the course of the academic year. Such insights will be key to helping improve educational and treatment policies on contemporary Canadian campuses.

\section{Funding}

Collection of the SLWBS data used in this study was funded by the Manitoba Gambling Research Program of Manitoba Liquor and Lotteries; however, the findings and conclusions of this paper are those solely of the authors and do not necessarily represent the views of Manitoba Liquor and Lotteries.

\section{References}

1. Adlaf E, Demers A, Gliksman L (2005) The 2004 Canadian campus survey. Toronto, Canada: Centre for Addiction and Mental Health.

2. Gliksman L, Newton-Taylor B, Adlaf E, Giesbrecht N (1997) Alcohol and other drug use by Ontario university students: The roles of gender, age, year of study, academic grades, place of residence and programme of study. Drugs: Education, Prevention and Policy 4: 117-129.

3. Gliksman L, Adlaf EM, Demers A, Newton-Taylor B (2003) Heavy drinking on Canadian campuses. Can J Public Health 94: 17-21. [Crossref]

4. Kwan MY, Faulkner GE, Arbour-Nicitopoulos KP, Cairney J (2013) Prevalence of health-risk behaviours among Canadian post-secondary students: descriptive results from the National College Health Assessment. BMC Public Health 13: 1.

5. Edkins T, Edgerton JD, Roberts LW (2016) Correlates of binge drinking in a sample of Canadian university students. (manuscript in submission).

6. Weitzman ER, Nelson TF, Wechsler H (2003) Taking up binge drinking in college: The influences of person, social group, and environment. J Adolesc Health 32: 26-35. [Crossref]
7. Nezlek JB, Pilkington CJ, Bilbro KG (1994) Moderation in excess: binge drinking and social interaction among college students. J Stud Alcohol 55: 342-351. [Crossref]

8. Jessor R, Costa FM, Krueger PM, Turbin MS (2006) A developmental study of heavy episodic drinking among college students: the role of psychosocial and behavioral protective and risk factors. J Stud Alcohol 67: 86-94. [Crossref]

9. Mohamed S, Ajmal M (2015) Multivariate analysis of binge drinking in young adult population: Data analysis of the 2007 Survey of Lifestyle, Attitude and Nutrition in Ireland. Psychiatry Clin Neurosci 69: 483-488. [Crossref]

10. Swendsen JD, Merikangas KR, Canino GJ, Kessler RC, Rubio-Stipec M, et al (1998) The comorbidity of alcoholism with anxiety and depressive disorders in four geographic communities. Compr Psychiatry 39: 176-184. [Crossref]

11. Townshend JM, Duka T (2005) Binge drinking, cognitive performance and mood in a population of young social drinkers. Alcoholism: Alcohol Clin Exp Res 29: 317-325. [Crossref]

12. Rasic D, Kisely S, Langille DB (2011) Protective associations of importance of religion and frequency of service attendance with depression risk, suicidal behaviours and substance use in adolescents in Nova Scotia, Canada. J Affect Disord 132: 389-395.

13. LaBrie RA1, Shaffer HJ, LaPlante DA, Wechsler H (2003) Correlates of college student gambling in the United States. J Am Coll Health 52: 53-62. [Crossref]

14. Townshend JM, Kambouropoulos N, Griffin A, Hunt FJ, Milani RM (2014) Binge drinking, reflection impulsivity, and unplanned sexual behavior: impaired decisionmaking in young social drinkers. Alcohol Clin Exp Res 38: 1143-1150.

15. Carlson SR, Johnson SC, Jacobs PC (2010) Disinhibited characteristics and binge drinking among university student drinkers. Addict Behav 35: 242-251. [Crossref]

16. Menard S (2010) Logistic Regression. Thousand Oaks, CA: Sage.

17. Wechsler H, Dowdall GW, Davenport A, Rimm EB (1995) A gender-specific measure of binge drinking among college students. Am J Public Health 85: 982-985. [Crossref]

18. Spitzer RL, Kroenke K, Williams JB, Löwe B (2004) A brief measure for assessing generalized anxiety disorder: the GAD-7. Arch Intern Med 166: 1092-1097. [Crossref]

19. Eaton WW, Smith C, Ybarra M, Muntaner C, Tien A (2004) Center for Epidemiologic Studies Depression Scale: review and revision (CESD and CESD-R).

20. Ebesutani C, Regan J, Smith A, Reise S, Higa-McMillan C, et al. (2012) The 10-item positive and negative affect schedule for children, child and parent shortened versions: application of item response theory for more efficient assessment. J Psychopathol Behav Assess 34: 191-203.

21. Diener E, Emmons RA, Larsen RJ, Griffin S (1985) The Satisfaction With Life Scale. $J$ Pers Assess 49: 71-75. [Crossref]

22. Keyes CLM (2009) Brief description of the mental health continuum short form (MHCSF). Atlanta, GA: Emory University.

23. Jessor R, Jessor SL (1977) Problem behavior and psychosocial development: A longitudinal study of youth. New York: Academic Press.

24. Martín-Albo J, Núñiez JL, Navarro JG, Grijalvo F (2007) The Rosenberg Self-Esteem Scale: translation and validation in university students. Span J Psychol 10: 458-467. [Crossref]

25. Stanford MS, Mathias CW, Dougherty DM, Lake SL, Anderson NE, et al. (2009) Fifty years of the Barratt Impulsiveness Scale: An update and review. Personality and Individual Differences 47: 385-395.

26. Plante TG, Boccaccini M (1997) Reliability and validity of the Santa Clara strength of religious faith questionnaire. Pastoral Psychology 45: 429-437.

27. White H, Labouvie E (2000) Longitudinal trends in problem drinking as measured by the Rutgers Alcohol Problem Index. Alcohol Clin Exp Res 24(5 Suppl 1).

28. Ferris JA, Wynne HJ (2001) The Canadian problem gambling index: User manual Toronto, Canada: Canadian Centre on Substance Abuse.

29. Davoren MP, Demant J, Shiely F, Perry IJ (2016) Alcohol consumption among university students in Ireland and the United Kingdom from 2002 to 2014: a systematic review. BMC Public Health 16: 1. [Crossref]

30. Wellman RJ, Contreras GA, Dugas EN, O'Loughlin EK, O’Loughlin JL (2014) Determinants of sustained binge drinking in young adults. Alcohol Clin Exp Res 38: 1409-1415. [Crossref]

31. Park CL (2004) Positive and negative consequences of alcohol consumption in college students. Addict Behav 29: 311-321. [Crossref] 
Edgerton JD (2016) Socio-demographic, behavioral, and mental health and wellbeing correlates of university student binge drinking: does frequency matter?

32. Nyström M (1992) Positive and negative consequences of alcohol drinking among young university students in Finland. Br J Addict 87: 715-722. [Crossref]

33. Crawford LA, Novak KB (2006) Alcohol abuse as a rite of passage: The effect of beliefs about alcohol and the college experience on undergraduates' drinking behaviors. J Drug Educ 36: 193-212. [Crossref]

34. Bennett ME, Miller JH, Woodall WG (1999) Drinking, binge drinking, and other drug use among southwestern undergraduates: Three-year trends. The American Journal of Drug and Alcohol Abuse 25: 331-350.

35. Knight JR, Wechsler H, Kuo M, Seibring M, Weitzman ER, et al. (2002) Alcohol abuse and dependence among U.S. college students. J Stud Alcohol 63: 263-270. [Crossref]

36. Arbour-Nicitopoulos KP, Kwan MY, Lowe D, Taman S, Faulkner GE (2010) Social norms of alcohol, smoking, and marijuana use within a Canadian university setting. $J$ Am Coll Health 59: 191-196. [Crossref]

37. Perkins HW (2007) Misperceptions of peer drinking norms in Canada: another look at the "reign of error" and its consequences among college students. Addict Behav 32: 2645-2656. [Crossref]
38. Wechsler H, Kuo M (2000) College students define binge drinking and estimate its prevalence: Results of a national survey. $J$ Am Coll Health 49: 57-64. [Crossref]

39. Chauvin CD (2011) Social norms and motivations associated with college binge drinking. Sociological Inquiry 82: 257-281.

40. Crawford LA, Novak KB (2010) Beliefs about alcohol and the college experience as moderators of the effects of perceived drinking norms on student alcohol use. Journal of Alcohol and Drug Education 54: 69-86.

41. Arnett JJ (2005) The developmental context of substance use in emerging adulthood. Journal of Drug Issues 35: 235-254.

42. Byrd KM (2016) Binge drinking in and out of college: An examination of social contro and differential association on binge drinking behaviors between college students and their non-college peers. Sociological Spectrum 36: 191-207.

43. Wechsler H, Nelson TF (2008) What we have learned from the Harvard School of Public Health College Alcohol Study: Focusing attention on college student alcohol consumption and the environmental conditions that promote it. J Stud Alcohol Drugs 69: 481-490. [Crossref]

Copyright: (C2016 Edgerton JD. This is an open-access article distributed under the terms of the Creative Commons Attribution License, which permits unrestricted use, distribution, and reproduction in any medium, provided the original author and source are credited. 